ror

SECCIÓN: Teorías geográficas, geografía de la cultura y la vida cotidiana
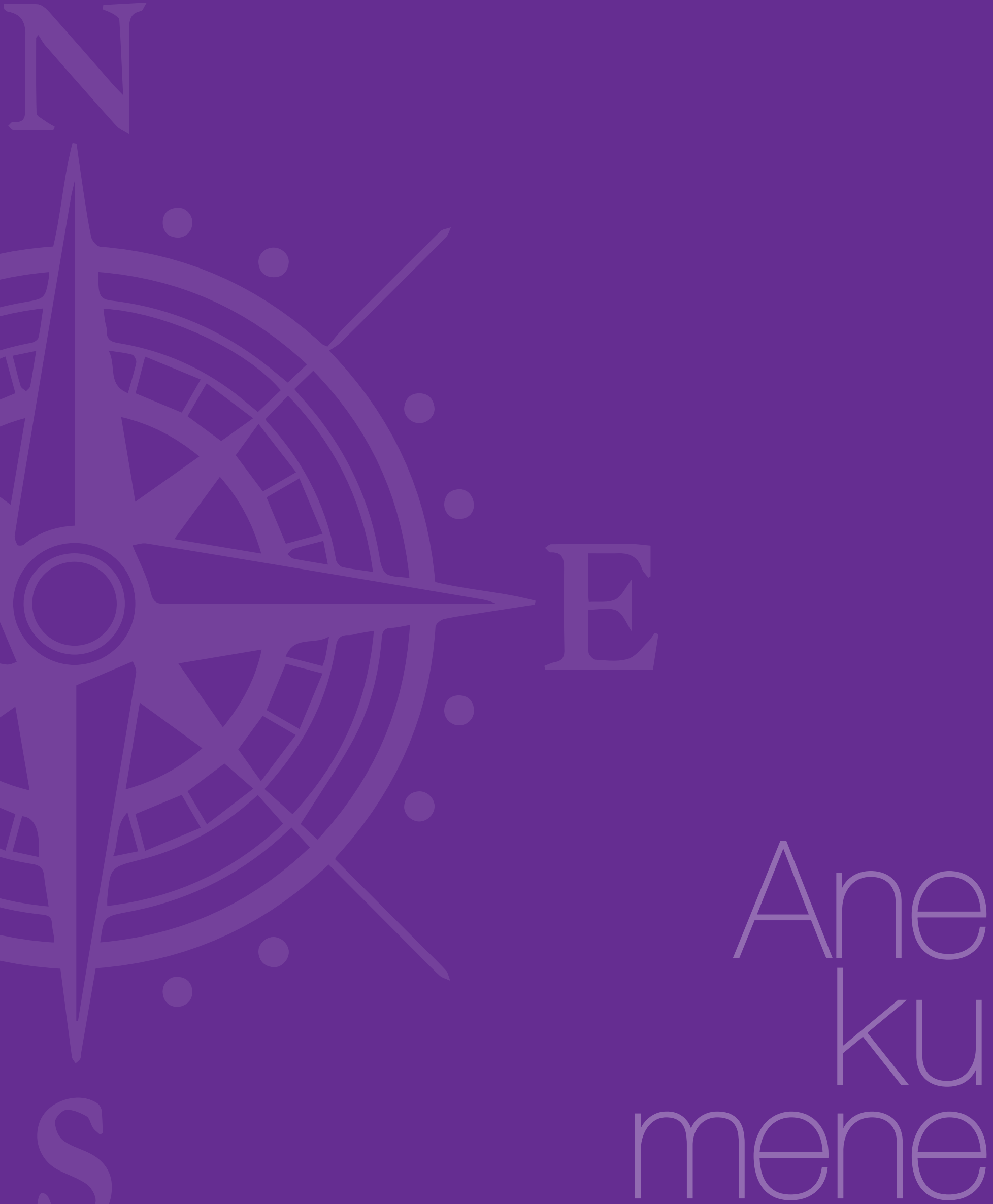


\section{Cartografia escolar, geografia e pensamento espacial na escola: reflexões sobre a dimensão social da cidade}

Cartografía escolar, geografía y pensamiento espacial en la escuela: reflexiones sobre la dimensión social de la ciudad

School Cartography, Geography and Spatial Thinking at School: Reflections on the Social Dimension of the City

Igor de Paula*

\begin{abstract}
Resumo
Este artigo pretende discutir o papel metodológico da cartografia e da geografia escolar na compreensão da cidade como espaço que reflete heterogeneidade de condições sociais e a escola como o lugar de tomada de conhecimento e consciência espacial. Dividido em três sessões, o texto atravessa por discussões que consideram a função comunicativa e política dos mapas, as relações entre a escola e a cidade, além de estabelecer alguns pressupostos de potência metodológica da emergente teoria do pensamento espacial em diálogo com a geografia.
\end{abstract}

\section{Palavras-chave}

Geografia; mapa; metodologia; espaço.

* Universidade de São Paulo. 


\section{Resumen}

Este artículo pretende discutir el papel metodológico de la cartografía y de la geografía escolar en la comprensión de la ciudad, entendida como espacio que refleja heterogeneidad de condiciones sociales, y la escuela como lugar de conocimiento y conciencia espacial. Dividido en tres apartados, el texto atraviesa por discusiones que consideran las funciones comunicativa y política de los mapas, las relaciones entre la escuela y la ciudad, además de establecer algunos presupuestos ligados a la emergente teoría del pensamiento espacial en diálogo con la geografía.

\begin{abstract}
The purpose of this article is to discuss the methodological role of cartography and school geography to comprehend the city-defined as a space that reflects heterogeneity of social conditions-, and the school as a place of knowledge and spatial awareness. Divided into three sections, the text goes through discussions that consider the communicative and political functions of the maps, the relationships between the school and the city, and establishes some assumptions concerning the emerging theory of spatial thought in dialogue with geography.
\end{abstract}

\section{Palabras clave}

Geografía; mapa; metodología; espacio.

\section{Keywords}

Geography; map; methodology; space. 


\section{Das distribuições aos padrões espaciais: 0 mapa é informação, conhecimento e poder}

$\mathrm{Na}$ Geografia, uma das perguntas mais frequentes feitas ao se ler um mapa é: onde as coisas estão? A essa resposta somam-se dúvidas complementares que na tentativa de completá-la indagam: como as coisas estão, quando as coisas estão, por quê as coisas estão. A questão da localização e a busca pelos padrões espaciais desde o século xıx acompanha a Geografia. Os vários mapas elaborados por A. Von Humboldt durante as investigações na América, por exemplo, são uma primeira demonstração de que para a Geografia, mais que qualquer coisa, importava naquele momento a diferenciação dos lugares a partir da descrição de suas características particulares. A linguagem cartográfica, em produtos como mapas, croquis e cartas, transmitia essas informações espaciais servindo de subsídio imagético, sobretudo aqueles mais interessados em um panorama espacial e territorial. Realizando um exercício analítico, a Carte du Mexique et des Pays Limitrophes Situes au Nord et a l'est (figura 1), de 1811, de A. Von Humboldt, imprime uma imagem espacial do México e de suas fronteiras com os Estados Unidos da América. ${ }^{1}$

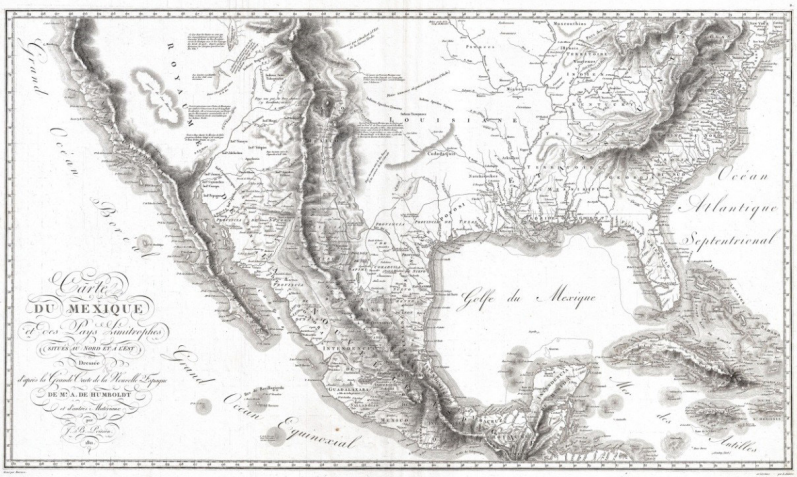

Figura 1. Carta do México e dos países limítrofes situados ao norte e a leste. Fonte: Wikimedia Commons (2018).

Somente localizar e caracterizar a superfície terrestre, em um primeiro momento, respondia bem aos desígnios científicos do período. Entretanto, o movimento constante de descobertas técnicas e tecnológicas aliado ao desenvolvimento da economia e do inchaço das forças produtivas colocou sobre a Geografia a necessidade de atribuir maior rigor metodológico às suas representações. Os métodos estatísticos e gráficos e a teoria da comunicação influenciaram diretamente a produção de teorias geográficas, principalmente nos dois primeiros quartos do

1 No mapa é possível observar, pelo sombreamento das hachuras de Humboldt, a orografia dos Apalaches (Nordeste dos Estados Unidos), dos Cânions (CentroOeste dos Estados Unidos) e das Cadeias Montanhosas da Costa do Pacífico (Costa Oeste dos Estados Unicos até a Península de Iucatã no México), além da hidrografia dos países, descrições importantes para conhecer melhor o território norte-americano. século $\mathrm{xx}$, surgindo nesse momento abordagens que privilegiaram as teorias locacionais com os trabalhos de A. Weber, W. Christaller, A. Losch, W. Isard, entre outros.

Esses trabalhos marcaram um momento em que a Geografia se preocupava em formular modelos e testar hipóteses que serviram de estratégias de economia espacial, difundidas globalmente. A cidade vista como e dentro de modelos espaciais, no caso das teorias dos lugares centrais de Christaller ${ }^{2}$ (figura 2), afirmou com o auxílio de representações espaciais o planejamento dos locais, emergindo, portanto, a seletividade dos lugares no desenvolvimento da economia, com base nos custos e relações espaciais.

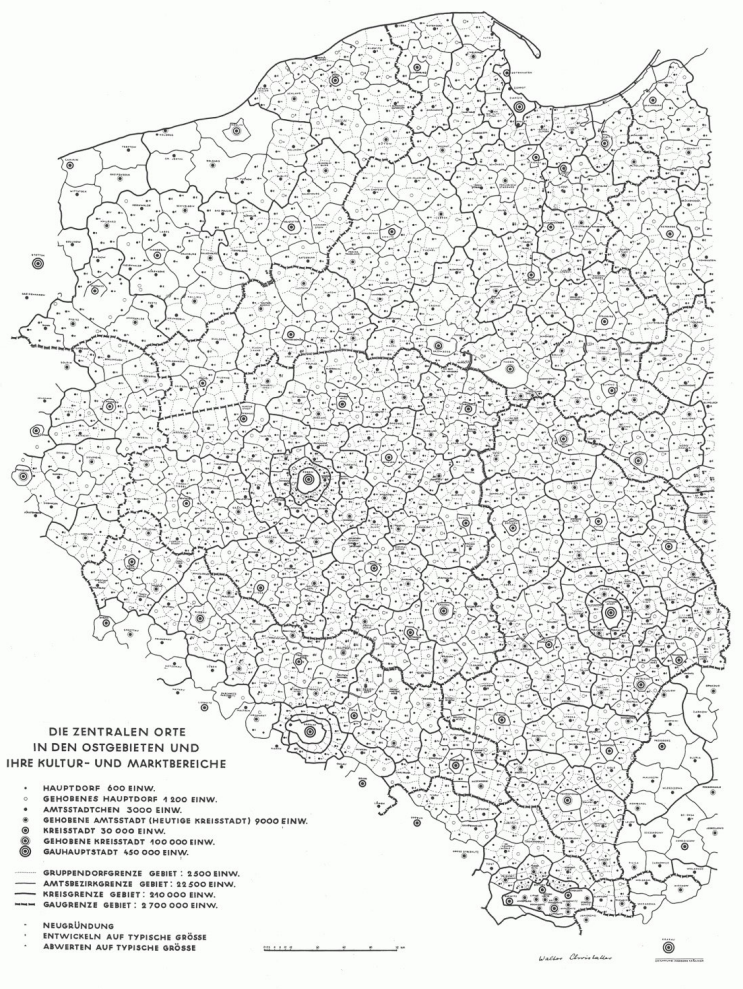

Figura 2. Lugares centrais nos territórios orientais em torno de suas áreas culturais e de mercado.

Fonte: Centrici (2018).

2 O mapa Die Zentralen Orte In Den Ostgebieten um ibre multur - Und Marktebereiche representa um modelo de Christaller da região central-oeste da Polônia, no século xx. Os três polos de destaque, envoltos por dois círculos, são Poznan, Breslávia e Lodz e retratam as centralidades das áreas culturais e de mercados nessa porção do território em 1941, um exemplo do conceito espacial de localização, identidade do lugar, hierarquia e rede. 
Os modelos espaciais não encerram a discussão de espaço na Geografia. Entretanto, tiveram papel decisivo na organização das sociedades urbano-industriais no século $x x$, transformando os mapas que deixaram de ser produtos descritivos dos elementos físicos dos conjuntos de paisagens observadas e se tornaram documentos informativos sistemáticos que localizavam e correlacionavam perfis de objetos para a criação de um modelo. Especialmente, Haggett (1972), quando cita o caso dos modelos, afirma que:

No trabalho científico o termo "modelo" tem, até certo ponto, todos os três significados. ${ }^{3}$ Os construtores de modelos científicos criam representações idealizadas da realidade com a finalidade de demonstrar algumas de suas propriedades. Os modelos são feitos necessariamente pela complexidade da realidade. Eles são um suporte para nosso entendimento e uma fonte de se trabalhar hipóteses em pesquisas. Eles não transmitem toda a verdade, mas uma útil e aparentemente compreensível parte dela. ${ }^{4}$ (p. 20).

As estruturas que permitiram a formulação teórica e empírica da Cartografia e, consequentemente, da Cartografia Escolar, baseiam-se nos códigos e linguagens da matemática. Isso não necessariamente significa reduzir a análise geográfica aos modelos, nem fazer da sociedade objeto explicável somente pela quantificação. Contudo, isto quer dizer valer-se de outras formas de conhecimentos e linguagens para permear camadas de compreensão sobre a realidade, permitindo que a análise e a crítica possam surgir antes pela criação de uma imagem, da forma, para que depois caminhemos para a complexidade da intenção, do conteúdo.

Não se trata, neste sentido, de tomarmos os modelos como conquista máxima da leitura geográfica, como se a interpretação espacial fosse possível somente ao criarmos modelos. Mas não podemos deixar de negar que o potencial da informação de um mapa pode ser infinitamente superior que a de um exaustivo relatório de muitas páginas. 0 mapa é também, como muito hoje se debate, um texto. Um texto, que para Harley (1989), faz parte de um contexto, seja no sentido perceptivo sensorial daquele que o lê, na concepção criativa e metodológica do que o elabora ou, e talvez, sobretudo, o processo/fenômeno espacial que ele está representando.

Para além dessas escolhas a missão dos mapas é transferir para o plano dos produtos, uma porção da superfície terrestre tida num quadro de referência e averiguada analiticamente a partir de certos objetivos e intenções de um discurso, pretendendo compreender a distribuição, as similaridades e dissimilaridades de objetos, práticas e relações geográficas, em distintos níveis de conjuntos espaciais, minimizando a distância entre a realidade e a representação por métodos estatísticos, matemáticos e gráficos (Bertin, 1986; Joly, 2013; Martinelli, 2016).

\footnotetext{
3 Haggett referiu-se as definições substantivas (com representação), adjetivas (como referências ideais) e verbais (como aquilo que está em demonstração).

4 Tradução minha.
}

Entretanto, considerando a leitura de Robinson e Petchenik (1976) sobre o mapa como sistema de comunicação e os diagramas de Board, Kolačný (figura 3), Muerhcke, entre outros, estabelecem um meio de anexar a interação entre a representação e o leitor:

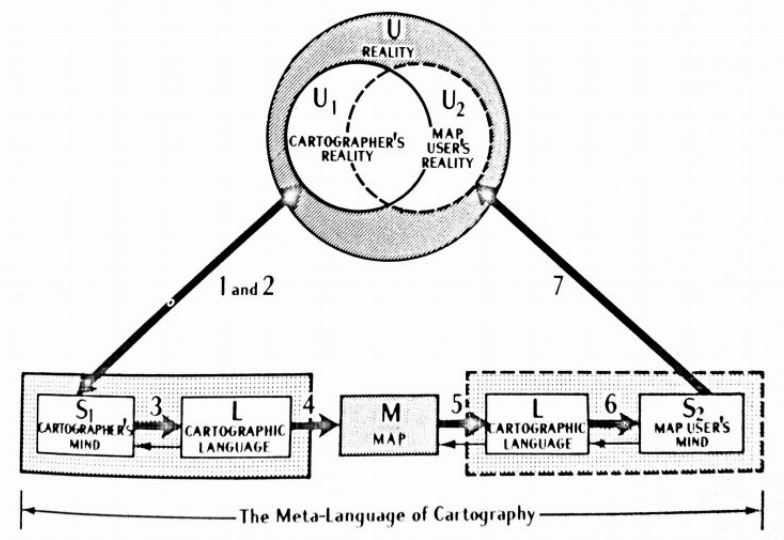

Figura 3. Diagrama de Kolačný.

Fonte: Robinson e Petchenik (1976).

O que quero neste momento é apenas definir os mapas e os modelos como transmissores estratégicos de informação espacial, portanto, ideias e ideais de poder, seja enquanto ferramenta de planejamento e execução das intenções ou panorama de observação do arranjo das estratégias ou das influências que ele pode desempenhar. Em qualquer um desses casos, o mapa é informação e, informação, é poder (Raffestin, 1993). o modelo do diagrama da comunicação cartográfica, da metalinguagem da cartografia, da realidade do cartógrafo e do usuário do mapa, não dá conta de explicar o todo da interação entre o produto e as reflexões que podem ser tomadas. Além da parte da realidade não abarcada na representação, cabe lembrar que o cartógrafo e o leitor não são produtores e usuários, mas sim sujeitos que vivem em um espaço cheio de relações históricas e socialmente em produção. A cidade pode ser o ponto de inflexão dessas conexões complexas.

\section{Educação geográfica e cartografia escolar: o elo espacial entre cidade, escola e mapa}

Tomaremos neste artigo a cidade como ponto de partida para apropriação do conhecimento geográfico e os mapas enquanto representações que podem introduzir e desvelar as particularidades da cidade. Pensar hoje a cidade como tema de investigação e produção de conhecimento sobre si mesma no espaço escolar, permite-nos pensá-la com profundi- 
dade. O que isso poderia ter a ver com a produção do espaço e as relações entre os estratos sociais? Qual a finalidade de se pensar um projeto de cidade ou de escola, no contexto de um país como o Brasil?

Justamente neste sentido de desnaturalizar a cidade e de não reduzi-la ao conjunto de disposições materiais, desconexa dos sentidos históricos, políticos e psicossociais, que se propõe realizar a Cartografia Escolar da cidade. Acreditamos que ler a cidade e interpretá-la depende primeiro do arranjo sistemático de suas informações; convém saber onde as coisas estão, como estão e por que estão, para que se possa conceber os espaços não como modelos homogêneos, mas como imagem heterogênea, correlacionada, contraditória e complementar em uma totalidade multiescalar. Esse seria, por exemplo, um dos acessos possíveis para se pensar a espacialidade diferencial e o papel do geógrafo e professor na escola contemporânea (Lacoste, 1988; Moreira, 2012).

Para isso, é nuclear entender que as informações espaciais, que também são sociais, dão pistas sobre como é a cidade, quem são seus sujeitos, como se relacionam e reproduzem as relações sociais; conhecer a cidade exige, por consequência, informar-se sobre ela. E qual seria um dos papeis da escola senão o de contribuir para que os sujeitos reconheçam e exerçam a cidadania? Diante das escolas que temos, quão próximo estamos desse objetivo?

Os conceitos de exclusão e de classe não aparecem aqui utilizados a bel-prazer. Há que se ter todo um cuidado ao definirmos um ou outro, portanto, condição ou situação social é mais promissora quando não se faz atravessamentos de robusteza teórico-epistêmica necessária. É por isso que escolhemos a conceitualização condição social, pois não foi eleita por simplicidade ou 'simplorismos', mas por poder caminhar em direção ao aprofundamento necessário. Nesses temas, J. de Souza Martins (2002) aponta para o cuidado ao interpretarmos as condições dos sujeitos e como eles se apropriam ou não do entendimento delas:

As pessoas e até os grupos sociais podem viver numa situação social problemática e adversa e, ao mesmo tempo ter dela uma compreensão insuficiente ou mesmo equivocada. Ou podem ter dela uma compreensão apropriada, num certo sentido objetivo, o que é muito mais raro. Isso depende muito da circunstância social e histórica. Há circunstâncias da crise que favorecem a justeza dessa compreensão. Há circunstâncias que não favorecem a compreensão e que distorcem a consciência social do sujeito (Martins, 2002, p. 26).

Caberia, portanto, não abandonar as aproximações críticas sobre a cidade. Mais que isso, como contribui J. de Souza Martins, realizar ponderações de categorias e conceitos que não coloquem sobre a realidade a visão restrita, em nosso caso, do geógrafo ou professor. Em outros termos, a vigilância para que não sobreponhamos sobre nosso objeto o que nós acreditamos ser a condição social dos sujeitos, a classe social a que eles supostamente pertencem, em exercícios de naufrágios conceituais que nos conduzirão ao afogamento na análise, a anunciação ou enunciação apenas das situações e questões sociais. Isso é importante para não transformar a Geografia em discurso facilmente absorvido, distorcido e contradito por aqueles que se opõem ao projeto de cidadania e saber que existe direta relação entre a visão científica de cidade, país e mundo e a formação do professor na Geografia que se aprende e ensina (Catling e Lee, 2017; Katuta, 2015).

Por isso dizer que conquistar o conhecimento científico geográfico da sociedade é ao mesmo tempo empoderar-se; pois os sujeitos que entendem a organização e as contradições espaciais de uma sociedade podem aprender, com o auxílio de outras experiências e saberes compartilhados em coletividade, a se organizarem. A consciência de um evento, fenômeno ou processo espacial decerto seja requisito para a conquista do espaço do cidadão (Damiani, 2010; Santos, 2007). E qual o lugar da escola que não o conhecimento científico e social? Essa é uma indagação importante em M. Young (2016):

Os estudantes podem "conhecer" muito sobre a sua própria cidade, por terem crescido nela; porém, a disciplina Geografia Ihes ensina um tipo muito diferente de conhecimento sobre "cidades"-um conhecimento que podem usar para fins de generalização. [...] $\mathrm{O}$ aspecto mais debatido do "conhecimento poderoso" é o poder. Poder é muito facilmente interpretado como "poder sobre" e, com frequência, como na política, em qualquer nível, poder sobre os outros. Entretanto, diferentes disciplinas oferecem aos alunos diferentes tipos de poder. Por exemplo, as ciências geram o poder da abstração e da generalização (P. 29).

O saber disciplinar pode sim oferecer esses diferentes tipos de poder. Mas não nos esqueçamos, e não parece ter também esquecido Young (2016), que ao longo da história das sociedades humanas os mapas percorreram as trajetórias que concederam, sobretudo às elites ou parte dela, as informações estratégicas e o conhecimento. As escolas ou instituições de educação compunham e faziam a manutenção da seletividade do processo de obter o conhecimento, conduzindo aqueles que obtinham os códigos específicos de acesso ao saber a capacidade de generalizar, criar, imaginar e seguir governando (Bourdieu, 2008; Burke, 2003).

O foco da discussão consiste em, especialmente nas escolas de juventudes em situação de vulnerabilidade, privação de cultura, lazer, saúde, segurança e conhecimento, garantir a vida com qualidade o acesso à educação digna e de qualidade e o entendimento do mundo/cidade em que se vive. Isso é cumprir com os direitos fundamentais e a função social da escola e a nossa enquanto professores e geógrafos. É nesse momento que uma metodologia não é só uma metodologia, mas um caminho a ser percorrido sobre como atingir objetivos de transformação social:

Ao entender a cartografia escolar como uma metodologia de ensinar geografia estabelecem-se as estratégias de aprendi- 
zagem para o desenvolvimento dos conteúdos que têm como objetivo desenvolver a capacidade de fazer análises geoespaciais para estabelecer conexões, relacionar e analisar os fenômenos. Não se trata de inventar métodos espaciais e mirabolantes para ensinar geografia. Trata-se de pensar estratégias que sejam significativas para os estudantes aprenderem a ler um mapa e ler a realidade (Castellar, 2017, p. 215)

A pergunta de Meirieu (1998) sobre como aprender? porventura encontraria razão no pensamento espacial como complemento metodológico da Cartografia na aprendizagem da Geografia e na prática da Educação Geográfica?

\section{0 pensamento espacial como complemento metodológico da cartografia escolar e da geografia}

Um dos primeiros pontos a serem amarrados aqui é que o pensamento espacial não deve ser confundido como sinônimo de Geografia nem Cartografia. Ele compõe uma discussão muito mais ampla e em efervescência que se desdobra nos mais diversos campos científicos como por exemplo a arquitetura, epidemiologia, ecologia, microbiologia, design, entre outros projetos e saberes que não estão fixos unicamente em uma disciplina. Não está circunscrito em limites teóricos disciplinares, portanto não é propriedade da Geografia. Dizer que estamos pensando espacialmente por simplesmente utilizarmos os mapas ou outros tipos de representações espaciais pode ser, pois, um equívoco. Ademais, pensar espacialmente, de acordo com o National Research Council (2006) exige uma metodologia que deve considerar: (1) representações espaciais, (2) conceitos espaciais e (3) processos de raciocínio.

O primeiro ponto estaria relacionado aos tipos de representação que permitem analisar questões espaciais, isto é, qual o produto que trará ao nível perceptível de quem observa os elementos espaciais, para que sejam identificados e interpretados. Poderíamos dizer que essas representações são as responsáveis pela forma na qual os eventos, fenômenos e processos aparecem para a análise. 0 segundo está relacionado ao próprio espaço, em seu sentido geométrico, não necessariamente geográfico. São conceitos que provocam e conduzem a análise, escolhendo os aspectos que podem explicar os eventos, fenômenos e processos. 0 terceiro quer dizer a ação, a qual movimento investigativo o raciocínio deve percorrer caminhos para solucionar as questões que se colocam diante do desconhecido.

Muitos foram os estudos que se propuseram a discutir teórica e metodologicamente a Cartografia Escolar, entre dissertações e teses, que criaram e seguem criando uma identidade de desenvolvimento de pesquisa ainda a consolidar esses conhecimentos. Podemos citar uma infinidade de trabalhos ricos que constroem a Cartografia Escolar no Brasil e que são indispensáveis à sistematização de conceitos e norteadores de práticas pedagógicas. Dentre eles, destacam-se os trabalhos de L. de Oliveira (2010), T. Paganelli, M. E. Simielli (1999), J. Le Sann, E Passini, R. Almeida, A. Katuta (2015), G. Girardi, F. Fonseca, entre outros.

Selecionaremos a metodologia de Simielli (1999), que parte, de níveis de atividade cartográfica com os mapas, partindo de raciocínios de localização para os de síntese, de uma menor para maior complexidade. Para ela existem dois eixos possíveis no trabalho cartográfico escolar, (1) a do aluno leitor crítico e (2) do aluno mapeador consciente. O primeiro eixo corresponde trabalhar com produtos cartográficos elaborados previamente, que não partem da confecção dos alunos, mas que são postos a análise:

No eixo em que os alunos trabalharão com produtos cartográficos já elaborados, mapas, cartas e plantas nos três níveis de leitura dos produtos cartográficos, a resultante final é o aluno leitor crítico. Portanto, neste encaminhamento o aluno terá condições de retirar do mapa os elementos fundamentais para a leitura das informações representadas (Simielli, 1999, p. 102).

O produto cartográfico escolhido, no exemplo do mapa, recolhe qualidade técnica e rigor metodológico a serem trabalhados em três níveis diferentes, (1) localização e análise, que é a localização do objeto representado e sua observação no sentido interpretativo mediante sua decodificação, (2) correlação de duas, três ou mais ocorrências no espaço, que é o relacionamento das informações espaciais seja em um mapa ou sobrepondo vários mapas dentro de um objetivo definido, (3) síntese geral do espaço relacionado, que é o produto do relacionamento das informações e a criação de uma concepção própria do objeto mediante agrupamento e redefinição de conjuntos espaciais.

No segundo eixo proposto por Simielli (1999), os alunos se propõem a elaborar um produto cartográfico, distinguindo-se do primeiro, ganhando em estratégia de inserção do sujeito na confecção do mapa, croqui ou maquete, etc.

Este segundo eixo terá como resultante um aluno mapeador consciente. A grande diferenciação em relação ao primeiro eixo é que o aluno vai participar efetivamente do processo de mapeamento. $O$ aluno será o confeccionador do mapa/croquis ou da maquete (Simielli 1999, p. 103).

Para que os alunos saibam, portanto, elaborar um produto cartográfico, é indispensável que eles antes aprendam a entendê-lo. Quando utilizamos o eixo do aluno leitor crítico é justamente isso que fazemos. Colocamos os procedimentos de interpretação do texto do mapa no planejamento das aulas e trabalhamos com o objetivo de decodificar os elementos da representação, para que seja possível reter a informação espacial. Esta metodologia considera tomar passos pedagógicos que incluem o conteúdo geográfico estudado com o mapa. Os três níveis de leitura podem entrar como objetivo de uma determinada sequência didática. 
Buscando conversar os níveis de atividade cartográfica, assinalamos, com base no Learning to Think Spatially, que as propostas do pensamento espacial consistem em dois níveis, o da proficiência espacial $\left(1^{\circ}\right.$ nível) e o da problematização espacial ( $2^{\circ}$ nível), ambos podendo aparecer completando-se na estruturação de uma possível prática pedagógica (NRC, 2006). Para tanto, os dois níveis estão sendo compreendidos para entendermos espacialmente a condição social na cidade, indo de encontro ao propósito do pensamento espacial que é o de “(...) criar uma geração de estudantes que (1) tenham o hábito de pensar espacialmente, (2) que possam praticar o pensamento espacial de forma esclarecida e bem informada, e (3) que adotem uma postura crítica ao pensamento espacial $^{5 "}$ (NRC, 2006, p.3).

Nesse caminho é essencial que se coloquem algumas questões: Como ter o hábito de pensar espacialmente? De que forma o pensamento espacial pode ser esclarecido e bem informado? Quais as posturas críticas em relação ao pensamento espacial? Não consigo pensar em respostas que não sejam intrínsecas ao projeto da Educação Geográfica e articuladas ao contexto social da cidade, das escolas e dos estudantes. A relação dos estudantes com a cidade, a escola e o conhecimento podem compor um projeto de aprendizagem que considere o imbricamento daquilo que se aprende com o que se vive, se é que é possível separar vida e conhecimento.

Entretanto, não só das condições sociais da cidade é que se faz a aprendizagem. Ela necessita passar por estratégias e movimentos coordenados na cognição. Uma das formas de buscar fazer isto considerando o objetivo de entender a condição social na cidade é utilizar a metodologia da Taxonomia do Pensamento Espacial, proposta por I. Jo e S. Bednarz $(2009)^{6}$, em diálogo com contribuições anteriores como R. Golledge, P. Gersmehl, D. Janelle e M. F. Goodchild, entre outros.

O que a proposta de Jo e Bednarz (2009) contribui de especial é justamente a ideia de hierarquizar os conceitos em categorias primitivas, simples e complexas, o caminho do aumento da exigência cognitiva dos raciocínios de entrada, processamento e saída, e o próprio relacionamento entre os três componentes do pensamento espacial, conceitos espaciais, processos de raciocínio e ferramentas de representação. Pensando nessas hierarquizações por complexidade e exigência de leitura, interpretação e generalização, é possível verificar o potencial do pensamento espacial e criar relacionamentos entre a metodologia de M.E. Simielli $(2010,1999)$ e Jo e Bednarz (2009).

\footnotetext{
5 Tradução minha.

6 Os vinte e quatro cubos são numerados referencialmente para exemplificar a hierarquia dos conceitos espaciais (na vertical), dos processos cognitivos (da
} esquerda para direita) e o uso ou não uso de representações (na diagonal).
Tabela 1. O relacionamento entre o pensar condição social na cidade, o nível da atividade cartográfica e a taxonomia do pensamento espacial.

\begin{tabular}{|c|c|c|}
\hline $\begin{array}{l}\text { Questões para pensar } \\
\text { espacialmente a } \\
\text { condição social da cidade }\end{array}$ & $\begin{array}{c}\text { Nível de } \\
\text { Atividade } \\
\text { Cartográfica } \\
\text { (Simielli, 1999) }\end{array}$ & $\begin{array}{c}\text { Taxonomia do } \\
\text { Pensamento Espacial } \\
\text { (Jo e Bednarz, 2009) }\end{array}$ \\
\hline $\begin{array}{l}\text { - Quais são os lugares } \\
\text { da cidade? } \\
\text { - Onde estão os lugares } \\
\text { da cidade? }\end{array}$ & Localização & $\begin{array}{l}\text { - Conceitos Espaciais } \\
\text { Primitivos } \\
\text { - Processos de } \\
\text { Raciocínio de Entrada }\end{array}$ \\
\hline $\begin{array}{l}\text { Quais as } \\
\text { características dos } \\
\text { lugares da cidade? } \\
\text { - O que reúne cada } \\
\text { lugar da cidade? }\end{array}$ & Análise & $\begin{array}{l}\text { - Conceitos Espaciais } \\
\text { Primitivos e Simples } \\
\text { - Processos de } \\
\text { Raciocínio de Entrada }\end{array}$ \\
\hline $\begin{array}{l}\text { Quais as semelhanças } \\
\text { e diferenças entre os } \\
\text { lugares da cidade? }\end{array}$ & $\begin{array}{l}\text { Análise e } \\
\text { Correlação }\end{array}$ & $\begin{array}{l}\text { - Conceitos Espaciais } \\
\text { Primitivos e Simples } \\
\text { - Processos de } \\
\text { Raciocínio de Entrada } \\
\text { e Processamento }\end{array}$ \\
\hline $\begin{array}{l}\text { É possível classificar } \\
\text { esses semelhantes e } \\
\text { diferentes os lugares } \\
\text { da cidade? } \\
\text { - Quais os padrões } \\
\text { espaciais } \\
\text { encontrados? }\end{array}$ & Correlação & $\begin{array}{l}\text { - Conceitos Espaciais } \\
\text { Primitivos, Simples e } \\
\text { Complexos } \\
\text { - Processos de } \\
\text { Raciocínio de Entrada } \\
\text { e Processamento }\end{array}$ \\
\hline $\begin{array}{l}\text { - Quais os tipos de } \\
\text { lugares da cidade? } \\
\text { - Quais as condições } \\
\text { sociais da cidade? } \\
\text { - O que elas nos dizem? } \\
\text { - O que elas } \\
\text { significam? } \\
\text { - Qual é o evento, } \\
\text { fenômeno } \\
\text { ou processo } \\
\text { geográfico que está } \\
\text { representado? } \\
\text { - Por que ocorre? } \\
\text { - O que fazer? }\end{array}$ & Síntese & $\begin{array}{l}\text { - Conceitos Espaciais } \\
\text { Primitivos, Simples e } \\
\text { Complexos } \\
\text { - Processos de } \\
\text { Raciocínio } \\
\text { de Entrada, } \\
\text { Processamento e } \\
\text { Saída }\end{array}$ \\
\hline
\end{tabular}

Fonte: Simielli (1999); Jo e Bednarz (2009).

Encontrar a espacialidade nos mapas temáticos, que fazem sempre parte de um projeto, como diria Fourez (2008), e representar os traços elementares das condições sociais na cidade, identificá-los, lê-los, interpretá-los, compará-los, classifica-los e padroniza-los é o projeto de formar a imagem heterogênea da cidade, desnaturalizando-a e desvendando sentidos que permitam a discussão no espaço escolar temas 
políticos, econômicos e culturais da contemporaneidade local e global. Não é demais dizer que grande parte das discussões postuladas neste artigo deverá aparecer doravante com muito mais profundidade analítica, teórica e metodológica.

Em conclusão parcial, os propósitos eminentemente inaugurais deste artigo apresentaram alguns itens teóricos e metodológicos que associam a condição social na cidade, enquanto produto do espaço, e sua interpretação geográfica pela Cartografia e pelo pensamento espacial. Muitas questões ficam voluntariamente a espera para que se desenrolem com maior profundidade em arguições que em breve alcançarão com mais força o debate original desta temática.

\section{Referências}

Bertin, J. (1986). A neográfica e o tratamento gráfico da informação. Curitiba: Editora da Universidade Federal do Paraná

Bourdieu, P. (2008). Os excluídos do interior. In P. Bourdieu (Ed.), A miséria do mundo (pp. 481-487). Petrópolis: Editora Vozes.

Burke, P. (2003). Uma História Social do Conhecimento: de Gutenberg a Diderot. Rio de Janeiro: Zahar.

Castellar, S. (2017). Cartografia Escolar e o Pensamento Espacial fortalecendo o conhecimento geográfico. Revista Brasileira de Educação em Geografia, 7(13), 207-232.

Catling, S. e Lee, J. (2017). English Geography Textbook Authors' Perspectives on Developing Pupils' Geographical Knowledge and Thinking. In C. Brooks, B. Graham e M. Fargher (Eds.) The Power of Geographical Thinking (pp. 211-234). USA: Springer.

Damiani, A. (2010). A geografia e a construção da cidadania. In R. Almeida (Ed.), Cartografia Escolar (pp. 50-61). São Paulo: Contexto.

Fourez, G. (2008). Como se elabora el conocimiento. Madrid: Narcea.

Haggett, P. (1972). Geography: a modern synthesis. New York: Harper \& Row.

Harley, B. (1989). Deconstructing the map. Cartographica, 26(2), 1-20.

Jo, I. e Bednarz, S. (2009). Evaluating Geography Textbook Questions from a Spatial Perspective: Using Concepts of Space, Tools of Representation, and Cognitive Process to Evaluate Spatiality. Journal of Geography, 108(1), 4-13.
Joly, F. (2013). A cartografia. Campinas: Papirus.

Katuta, A. (2015). A linguagem cartográfica no ensino superior e básico. In N. Pontuschka e A. Oliveira (Eds.), Geografia em perspectiva (pp. 133-140). São Paulo: Contexto.

Lacoste, Y. (1988). A geografia: isso serve, em primeiro lugar, para fazer a guerra. Campinas: Papirus.

Martinelli, M. (2016). Mapas da geografia e cartografia temática. São Paulo: Contexto.

Martins, J. (2002). A sociedade vista do abismo: novos estudos sobre exclusão, pobreza e classes sociais. Petrópolis: Vozes.

Meirieu, P. (1998). Aprender...sim, mas como? Porto Alegre: Artmed.

Moreira, R. (2012). Para onde vai o pensamento geográfico?: por uma epistemologia crítica. São Paulo: Contexto.

National Research Council (NRC). (2006). Learning to Think Spatially. Washington, D. C.: The National Academies Press.

Oliveira, L. (2010). Estudo metodológico e cognitivo do mapa. In R. Almeida (Ed.), Cartografia Escolar (pp. 15-42). São Paulo: Contexto.

Raffestin, C. (1993). Por uma geografia do poder. São Paulo: Ática.

Robinson, A. e Petchenik, B. (1976). The Nature of Maps: Essays toward Understanding Maps and Mapping. Chicago: University of Chicago Press.

Santos, M. (2007). O Espaço do Cidadão. São Paulo: Universidade de São Paulo.

Simielli, M. (1999). Cartografia no ensino fundamental e médio. In A. Carlos (Ed.), A Geografia na Sala de Aula (pp. 92-108). São Paulo: Contexto.

Simielli, M. (2010). O mapa como meio de comunicação e alfabetização cartográfica. In R. Almeida, Cartografia Escolar (pp. 145-172). São Paulo: Contexto, 2010.

Young, M. (2016). Por que o conhecimento é importante para as escolas do século xxI? Cadernos de Pesquisa, 46(159), 18-37. 